\title{
Patient Concerns Inventory for head and neck cancer: Brazilian cultural adaptation
}

Ivy Jungerman ${ }^{1}$, Julia Toyota ${ }^{2}$, Neyller Patriota Montoni ${ }^{3}$, Elma Heitmann Mares Azevedo ${ }^{4}$, Renata Ligia Vieira Guedes ${ }^{3}$,

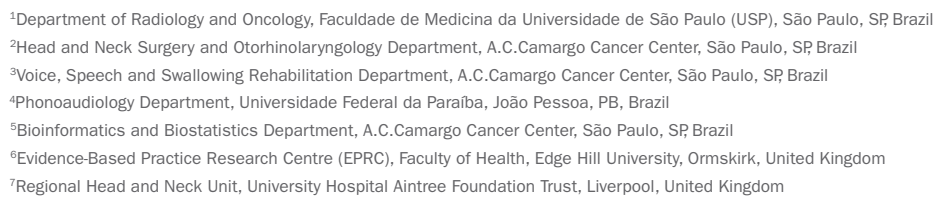

Study conducted at the Head and Neck Surgery and Otorhinolaryngology Department, A.C.Camargo Cancer Center, São Paulo, SP, Brazil

Article received: $11 / 4 / 2016$ Accepted for publication: 12/1/2016

*Correspondence: A.C.Camargo Cancer Center Address: Rua Professor Antonio Prudente, 211 São Paulo, SP - Brazil Postal code: 01509-900 jgvartanian@uol.com.br

\section{SUMmARY}

Objective: The purpose of this study was to translate, culturally validate and evaluate the Patients Concerns Inventory - Head and Neck (PCI-H\&N) in a consecutive series of Brazilian patients.

Method: This study included adult patients treated for upper aerodigestive tract (UADT) cancer. The translation and cultural adaptation of the PCI-H\&N followed internationally accepted guidelines and included a pretest sample of patients that completed the first Brazilian Portuguese version of the PCI. Use, feasibility and acceptability of the PCI were tested subsequently in a consecutive series of UADT cancer patients that completed the final Brazilian Portuguese version of the PCI and a Brazilian Portuguese version of the University of Washington Quality of Life Questionnaire (UW-QOL). Associations between physical and socio-emotional composite scores from the UW-QOL and the PCI were analyzed. Results: Twenty (20) patients participated in the pretest survey (translation and cultural adaptation process), and 84 patients were analyzed in the cultural validation study. Issues most selected were: fear of cancer returning, dry mouth, chewing/ eating, speech/voice/being understood, swallowing, dental health/teeth, anxiety, fatigue/tiredness, taste, and fear of adverse events. The three specialists most selected by the patients for further consultation were speech therapist, dentist and psychologist. Statistically significant relationships between PCI and UW-QOL were found.

Conclusion: The translation and cultural adaptation of the PCI into Brazilian Portuguese language was successful, and the results demonstrate its feasibility and usefulness, making this a valuable tool for use among the Brazilian head and neck cancer population.

Keywords: surveys and questionnaires, quality of life, head and neck neoplasms, validity and reliability, outcomes research.

\section{INTRODUCTION}

Worldwide, approximately 650,000 people per year are diagnosed with head and neck cancer. ${ }^{1}$ The city of São Paulo has one of the highest incidence rates of laryngeal and oral cancer worldwide. ${ }^{2}$

Head and neck cancer and its treatment can cause significant changes in vital functions related to feeding, communication and breathing of affected patients, as well as to an individual's self-image. Such alterations can have devastating consequences on the patient's quality of life and also on their families. ${ }^{3-5}$ The current focus of head and neck oncology is to eliminate cancer, prolong survival, obtain better functional outcomes and preserve or restore the quality of life (QOL) of affected patients. Studies of QOL using generic or specific measures usually generate data and information about the disease and the overall 
impact of its treatment on the patient, including data that could be used to improve treatment support, optimize patient care, define rehabilitation necessity and goals, identify problems and preferences of patients, and also facilitate communication between patients and doctors. ${ }^{6-9}$

In conjunction with the Merseyside Regional Head $\&$ Neck Cancer Centre Support Group, Rogers et al. ${ }^{10,11}$ and Ghazali et al. ${ }^{12}$ developed the Patient Concerns Inventory - Head and Neck (PCI-H\&N), which has been included in the British $\mathrm{H} \& \mathrm{~N}$ National Annual audit (DAHNO) as an indicator of quality of care. It consists of an inventory based on the collection of items from various health-related quality of life (HRQOL) questionnaires. The PCI is a carefully designed $\mathrm{H} \& \mathrm{~N}$ cancer-specific checklist intended to be used in consultations as part of routine outpatient care. It is holistic, self-administered and designed to achieve a more patient-focused and patient-directed medical consultation, leading to more shared decision-making and potentially better patient support and outcomes. Patients select items from the checklist that they want to discuss during the consultation and also select health professionals that they would like to see during their outpatient visit or be referred to.

The purposes of the present study were to adapt and culturally validate the PCI-H\&N into Brazilian Portuguese language and to evaluate its use in a series of patients treated for head and neck cancer (HNC) in a referral cancer center in Brazil.

\section{Method}

\section{The instrument description}

The first part of the original English version of the PCI has 57 items grouped into five domains: physical and functional well-being (29 items), treatment-related (four items), social assistance and welfare (nine items), psychological, emotional and spiritual well-being (14 items), and other (free text). The second part consists of a list of 17 specialists, also grouped into five domains: physical and functional well-being (eight specialists), treatment-related (three specialists), social assistance and welfare (three specialists), psychological, emotional and spiritual well-being (three specialists), and others (free text). In both parts of the inventory, patients can select as many items and specialists as they would like.

It is important to highlight that the PCI is a checklist of issues that patients wish to talk about in their clinical consultation and is not a measure of the level of concern per se. Patients can have concerns and still not want to discuss them. It has no rating or score.

\section{Translation and adaptation process}

The translation and cultural adaptation of the PCI followed internationally accepted guidelines. ${ }^{13,14}$ Initially, two bicultural experts and translators, who were experts in the area of healthcare, translated the original English version of the PCI into Brazilian Portuguese. A third bicultural expert compared the two versions, and a consensus version was reached. The consensus-translated version of the Brazilian Portuguese PCI was then back-translated into English by two additional bicultural experts and translators who were native English speakers in collaboration with one of the authors (SNR). To confirm the cross-cultural equivalence of the original and translated versions for semantic, idiomatic, experiential and conceptual aspects, a committee formed by three healthcare professionals with experience in $\mathrm{HNC}$ revised the final version, comparing it to the original one. Any discrepancies between the original and back-translated versions were resolved by repeating the process as needed.

A pretest survey was performed.

\section{Pretest survey}

The inclusion criteria for the pretest survey were: patients 18 years of age or older who were treated for upper aerodigestive tract (UADT) cancers regardless of the histological type or tumor staging. Exclusion criteria: Patients with a diagnosis of thyroid cancer or neurological changes, and/ or deficits in comprehension and/or ability to communicate, as well as individuals who reported being physically and/or psychologically unable to answer the questionnaire.

A series of 20 eligible patients completed the Brazilian Portuguese PCI version for the pretest survey. Informed consent was obtained from all patients enrolled in this pretest survey.

During this pretest survey, patients were asked about possible difficulties in interpreting any words or expressions translated in the Brazilian version of the PCI, as well as limitations to complete the questionnaire. If any specific difficulty to complete the inventory was reported by more than one patient, a meeting among the research team members (Brazilian authors) was performed to adapt and modify such item as needed.

\section{Cultural validation study}

A consecutive series of UADT cancer patients meeting the same inclusion and exclusion criteria of the pretest survey completed the final version of the PCI and also the Brazilian Portuguese validated form of the University of Washington Quality of Life Questionnaire (UW-QOLv4). ${ }^{15,16}$ Informed consent was obtained from all enrolled patients. 
Based on the literature available for this type of research, there is no consensus and no general criteria to establish the required sample size for a patient-reported outcome instrument validation study. A sample size of at least 50 to 100 participants is generally recommended. These numbers of subjects ensure stability of the variance-covariance matrix. ${ }^{17}$

A psychometrically valid survey instrument will assess what it is meant to be measured, and the PCI evaluates whether patients want to discuss items - in practice, they either want to discuss an item or they don't. Due to its "checklist" format, PCI is not suited for psychometric testing in the usual sense applied to the majority of HRQOL survey instruments. Translation and cultural adaptation are the most important steps to assure that the properties of the original instrument are maintained in another language. Content validity is the most relevant of the PCI properties, reflecting a belief that the questions adequately cover the content of the field of study. In the original language format, content validity was thoroughly established, which ought to be maintained after proper translation into Brazilian Portuguese and subsequent verification through back-translation.

However, even considering that the most important step of cultural validation of PCI into Brazilian Portuguese is the rigorous process of translation and back-translation, we decided to test the construct validity of the Brazilian version by comparing its results with the UW-QOL scores. Construct validity is present if the scale behaves according to hypothesized relationships. We hypothesized that the composite score of the UW-QOL should be associated and correlated with the number of issues selected for discussion by the patients on the PCI.

The validated Brazilian Portuguese format of the UW-QOLv4 was used because it is a disease-specific, concise and well-validated QOL questionnaire and because its domains overlap with many of the concerns listed on the PCI. Each domain item on the UW-QOL scale is scored from 0 to 100 , with the composite score being the mean of the 12 domains. Higher scores are indicative of better QOL. In our study, the UW-QOL results were analyzed considering two composite scores: "physical function" (simple average of the domain scores for swallowing, chewing, speech, saliva, taste and appearance) and "socio-emotional function" (simple average of the domain scores for activity, recreation, pain, mood, anxiety and shoulders). ${ }^{15}$

\section{Statistical analysis}

Nonparametric Mann-Whitney test (two categories) or Kruskal-Wallis test (three categories) were used to evalu- ate the association between number of items/specialists selected and patient characteristics. The Mann-Whitney test was also used to associate the composite scores of the UW-QOL (physical, socio-emotional) with the specific items/specialists selected by the patients. The associations between the scores of the UW-QOL and age, time of diagnosis and the number of items/specialists selected were assessed using Spearman's correlation coefficient. Associations between the specific items/specialists selected and patient characteristics were evaluated using Chi-square test or Fisher's exact test. The level of significance was set to $1 \%$. The software used was $\mathrm{R}$ version 3.0.1. ( $\mathrm{R}$ is a language and environment for statistical computing and graphics. $\mathrm{R}$ provides a wide variety of statistical and graphical techniques, and is highly extensible. It is available as free software under the terms of the Free Software Foundation's GNU General Public License in source code form).

\section{Results}

Translation process and pretest survey

As part of the translation and adaptation process, we conducted a pretest survey with 20 patients with UADT cancers (eight oral cavity, six larynx, two oropharynx, three nasopharynx and one maxillary sinus) who completed the Brazilian Portuguese version of the PCI.

There were no significant discrepancies between the translation and back-translation versions, despite the grammatical and cultural differences between the Brazilian and English populations.

However, in the pretest survey, some patients did not understand the meaning of the following terms in the first translated version: mucous, deglutition, smell, taste, percutaneous gastrostomy (PEG), fear of adverse events and coping strategies. The terms home care/Family Health Program (originally described as home care/district nurse) were erroneously interpreted as any family member or person providing help/medical assistance. The term "activity" was interpreted differently by patients, being understood as physical exercises or as activities of daily living. Patients were also confused by the terms salivation and dry mouth and were unable to distinguish and clearly define them.

Following the adequacy of equivalence and adaptations for the Brazilian population, the consensus research team then constructed a final version in Brazilian Portuguese. This final version was defined replacing or supplementing the terms that were misunderstood, misinterpreted or indistinguishable, for phlegm/secretions, swallowing (deglutition), olfaction (smell), taste (sense 
of flavor), feeding tube, fear of adverse events and strategies to cope with the illness and treatment, specialist care at home, physical activity and too much salivation.

In the pretest survey, among the specialists listed in the original PCI version, dental hygienist and chaplain were not easily identified by patients, as well as emotional support therapists (a clinical specialty just below the level of a psychologist that exists in the United Kingdom, but not in Brazil). For the final consensus version, the specialty dental hygienist was removed, chaplain was replaced by the religious authority/leader of their religion, and psychologist and psychiatrist were added.

\section{Cultural validation study}

A consecutive series of 84 patients with UADT cancers were enrolled between February 2013 and June 2013 for this study, and they completed the final Brazilian Portuguese version of the $\mathrm{PCI}$ and the Brazilian Portuguese version of the UW-QOLv4. Most patients were male (74\%), mean age of 62 years (ranging from 36 to 89 years), with low education level (57\%) and histologically confirmed squamous cell carcinoma (SCC) (89\%). Tumor sites were the oral cavity in 35 patients ( $42 \%$ ), larynx in 20 patients $(24 \%)$, oropharynx in 19 patients (23\%), nasopharynx in three patients (4\%), hypopharynx in three patients (4\%), nasal and paranasal sinuses in two patients (2\%), and occult primary tumors in two patients (2\%). Most of them presented with tumors at an advanced stage: T3 in 19 patients $(23 \%)$ and $\mathrm{T} 4$ in $25(30 \%)$. Half of the patient sample was clinically negative for lymph node involvement (50\%), and almost all patients were clinically negative for distant metastasis (96\%). Regarding time interval between treatment and questionnaire completion, 25 patients (30\%) marked less than 12 months, 22 patients (26\%) between 12 and 36 months and 37 patients (44\%) for 36 months or more. Thirty-four (34) patients (40\%) underwent surgery and radiotherapy, 29 (35\%) underwent primary radiotherapy and 21 (25\%) underwent surgery only. Thirty-five (35) patients (42\%) underwent chemotherapy at some point during their treatment.

The time required to fill out the PCI ranged from 6 to 20 minutes (mean: 13 minutes). The frequency of the items indicated on the PCI is described in Figures 1 and 2. Among the items listed in the inventory, issues selected most frequently by patients for discussion included the following: fear of cancer returning (57\%), dry mouth (45\%), chewing/eating (44\%), speech/voice/being understood (43\%), swallowing (40\%), dental health/teeth (36\%), anxiety (31\%), fatigue/tiredness (30\%), taste (sense of flavor) $(30 \%)$ and fear of adverse events (30\%) (Figure 1). The three specialists most selected by patients were speech therapist by 22 patients (26\%), dentist by 20 patients $(24 \%)$ and psychologist by 15 patients (18\%) (Figure 2). The median (interquartile range - IQR) number of PCI items selected was eight (5-13), ranging between 0 and 42 items, with 75 patients $(89 \%)$ selecting at least one item. The median (IQR) number of specialists indicated was one $(0-2)$, ranging between zero and eight specialists, with 30 patients (36\%) selecting at least one specialist.

The number of concerns and specialists selected correlated weakly with the time of diagnosis $(-0.29, \mathrm{p}=0.007$ and $-0.28, \mathrm{p}=0.01$ ), with more items selected in the case of shorter interval between the end of treatment and participation in the study, while patient age correlated with the number of specialists selected $(-0.28, \mathrm{p}=0.009)$ in that younger patients selected a greater number of specialists (Table 1). There were no other significant association of clinical variables studied with the number of items and specialists selected.

The mean composite score for UW-QOL was 73 (standard deviation [SD], 20). For the physical and socio-emotional domains, the scores were respectively, 78 (21) and 67 (24). The physical and socio-emotional domains of the UW-QOL were significantly correlated with the number of concerns selected $(-0.46$ and -0.45 , both $\mathrm{p}<0.001)$ and with the number of specialists selected $(-0.46, \mathrm{p}<0.001$ and $-0.33, \mathrm{p}=0.002$ ). The worse the UW-QOL score, the more PCI items were selected.

Significant associations between specific issues and specialists selected with patient characteristics and with the physical and socio-emotional domains of the UW-QOL were detected. Patients under 55 years of age selected more items of dental health $(50 \%)$ and fear of cancer returning $(75 \%)$ than older patients. Females were more than twice as likely as males to select sleep and anxiety, with $8 / 22$ (36\%) and 12/22 (55\%), respectively. Patients with posttreatment interval of 12 months or less selected considerably more items than patients with longer than 12 months treatment interval regarding to appetite (40\%), cancer treatment (48\%), use of a feeding tube (32\%), wound healing $(16 \%)$ support for the family (16\%), and specialist dietician (28\%) and speech therapist (52\%). Appetite (42\%) and appearance (46\%) were about three times more likely to be selected by patients who had more extensive neck disease (N2-N3). Individuals undergoing reconstruction indicated excessive salivation (22\%) more frequently than those without reconstruction (3\%). The item dry mouth was indicated by $16(35 \%)$ patients who underwent radiotherapy and 17 (81\%) who did not undergo surgery. In addition, 19 patients (66\%) who underwent primary radiotherapy (RT) selected dry mouth, and one-third of 


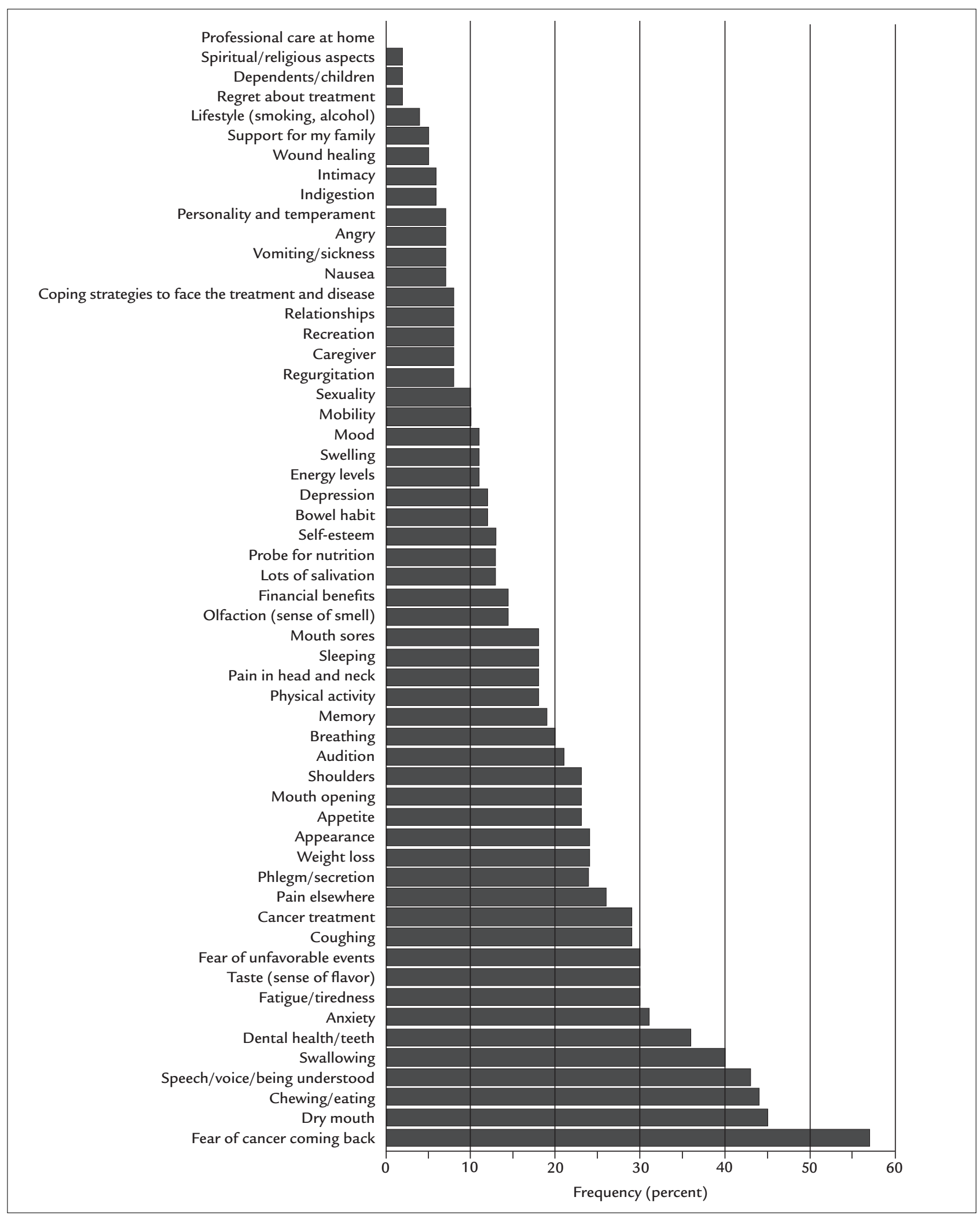

FIGURE 1 Patient Concerns Inventory issues selected most frequently by patients. 


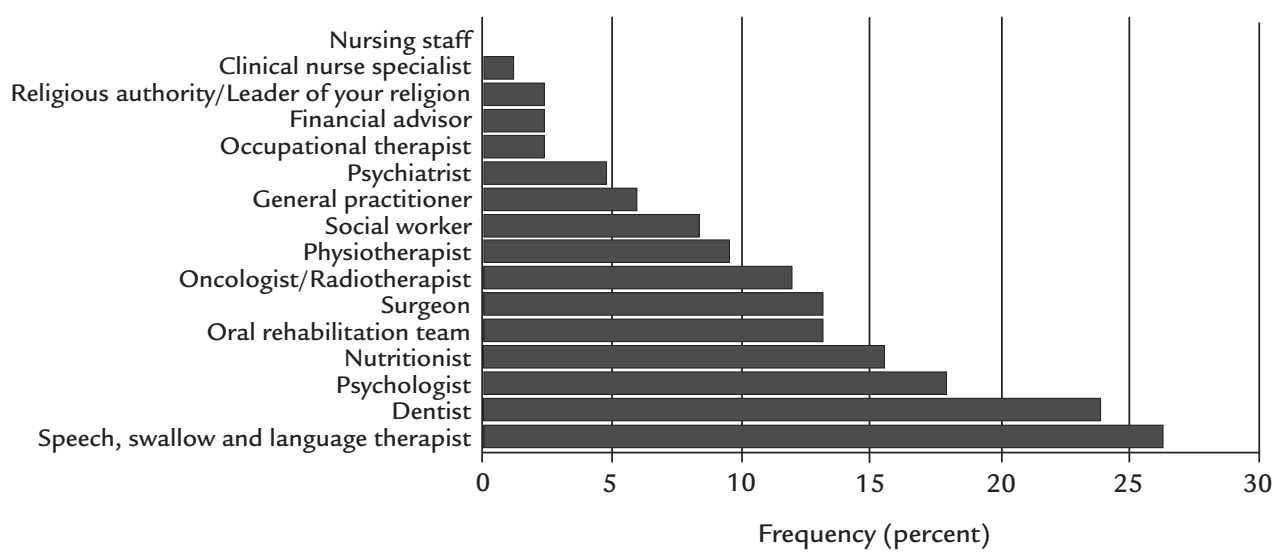

FIGURE 2 The specialists selected most by patients.

TABLE 1 Patients characteristics and the number of items and professional specialists selected in the $\mathrm{PCl}(\mathrm{n}=84)$.

\begin{tabular}{|c|c|c|c|c|c|c|c|c|c|c|}
\hline & & \multicolumn{4}{|c|}{ Number of issues selected } & \multicolumn{4}{|c|}{ Number of professionals selected } \\
\hline & & \multirow[b]{2}{*}{$\mathbf{n}$} & \multirow[b]{2}{*}{ Median } & \multirow[b]{2}{*}{ IQR } & \multicolumn{2}{|c|}{$5+$ items } & \multirow[b]{2}{*}{ Median } & \multirow[b]{2}{*}{ IQR } & \multicolumn{2}{|c|}{$2+$ professionals } \\
\hline & & & & & $\%$ & $\mathbf{n}$ & & & $\%$ & $\mathbf{n}$ \\
\hline \multirow[t]{3}{*}{ Age $^{*}$} & $<55$ & 20 & 9 & $5-12$ & 80 & 16 & 2 & $0-4$ & 60 & 12 \\
\hline & $55-64$ & 27 & 7 & $4-12$ & 67 & 18 & 1 & $0-3$ & 37 & 10 \\
\hline & $\geq 65$ & 37 & 9 & $5-14$ & 78 & 29 & 0 & $0-1$ & 22 & 8 \\
\hline \multirow[t]{2}{*}{ Gender } & Male & 62 & 8 & $5-13$ & 76 & 47 & 0 & $0-2$ & 31 & 19 \\
\hline & Female & 22 & 10 & $4-15$ & 73 & 16 & 1.5 & $1-4$ & 50 & 11 \\
\hline \multirow[t]{4}{*}{ Site of tumor } & Oral cavity & 35 & 8 & $4-13$ & 71 & 25 & 1 & $0-3$ & 31 & 11 \\
\hline & Oropharynx & 19 & 9 & $5-15$ & 79 & 15 & 1 & $0-3$ & 47 & 9 \\
\hline & Larynx & 20 & 8 & $5-10$ & 75 & 15 & 0 & $0-2$ & 30 & 6 \\
\hline & Others & 10 & 10 & $7-13$ & 80 & 8 & 1 & $0-2$ & 40 & 4 \\
\hline \multirow{3}{*}{$\begin{array}{l}\text { Time from diagnosis }{ }^{+} \\
\text {(months) }\end{array}$} & $<12$ & 25 & 13 & $7-15$ & 84 & 21 & 2 & $0-4$ & 60 & 15 \\
\hline & $12-35$ & 22 & 9 & $4-12$ & 73 & 16 & 0.5 & $0-2$ & 36 & 8 \\
\hline & $\geq 36$ & 37 & 7 & $4-11$ & 70 & 26 & 0 & $0-1$ & 19 & 7 \\
\hline \multirow[t]{2}{*}{ T stage } & T1_2 & 38 & 7.5 & $4-12$ & 66 & 25 & 1 & $0-2$ & 37 & 14 \\
\hline & T3_4 & 44 & 8.5 & $6-14$ & 82 & 36 & 0.5 & $0-3$ & 34 & 15 \\
\hline \multirow[t]{2}{*}{$\mathrm{N}$ stage } & N0_1 & 59 & 7 & $4-12$ & 69 & 41 & 0 & $0-2$ & 27 & 16 \\
\hline & N2_3 & 24 & 11 & $8-15$ & 88 & 21 & 2 & $0-3$ & 54 & 13 \\
\hline \multirow[t]{2}{*}{ Reconstruction } & No & 38 & 8.5 & $4-12$ & 68 & 26 & 1 & $0-2$ & 34 & 13 \\
\hline & Yes & 46 & 8 & $5-14$ & 80 & 37 & 1 & $0-3$ & 37 & 17 \\
\hline \multirow[t]{2}{*}{ RT } & No & 16 & 8.5 & $4-16$ & 63 & 10 & 1 & $0-2$ & 38 & 6 \\
\hline & Yes & 68 & 8 & $5-13$ & 78 & 53 & 1 & $0-2$ & 35 & 24 \\
\hline \multirow[t]{3}{*}{ Treatment } & Surgery, no RT & 21 & 10 & $4-17$ & 67 & 14 & 1 & $0-3$ & 48 & 10 \\
\hline & Surgery \& RT & 34 & 7 & $5-11$ & 76 & 26 & 0 & $0-1$ & 21 & 7 \\
\hline & Primary RT & 29 & 9 & $6-13$ & 79 & 23 & 1 & $0-3$ & 45 & 13 \\
\hline
\end{tabular}


TABLE 1 (Cont.) Patients characteristics and the number of items and professional specialists selected in the $\mathrm{PCl}(\mathrm{n}=84)$.

\begin{tabular}{|c|c|c|c|c|c|c|c|c|c|c|}
\hline & & & \multicolumn{4}{|c|}{ Number of issues selected } & \multicolumn{4}{|c|}{ Number of professionals selected } \\
\hline & & \multirow[b]{2}{*}{$\mathbf{n}$} & \multicolumn{4}{|c|}{$5+$ items } & \multirow[b]{2}{*}{ Median } & \multirow[b]{2}{*}{ IQR } & \multicolumn{2}{|c|}{$2+$ professionals } \\
\hline & & & Median & IQR & $\%$ & $\mathbf{n}$ & & & $\%$ & $\mathbf{n}$ \\
\hline \multirow{4}{*}{$\begin{array}{l}\text { Physical function } \\
\left(\text { UW-QOL) }{ }^{++* *}\right.\end{array}$} & $<50$ & 9 & 9 & $8-16$ & 100 & 9 & 3 & $2-4$ & 89 & 8 \\
\hline & $50-74$ & 19 & 12 & $9-16$ & 84 & 16 & 1 & $0-5$ & 47 & 9 \\
\hline & $75-89$ & 26 & 9 & $4-13$ & 73 & 19 & 1 & $0-2$ & 38 & 10 \\
\hline & $90+$ & 30 & 6 & $3-9$ & 63 & 19 & 0 & $0-1$ & 10 & 3 \\
\hline \multirow{4}{*}{$\begin{array}{l}\text { Social-emotional } \\
(\mathrm{UW}-\mathrm{QOL})^{++*}\end{array}$} & $<50$ & 20 & 12 & 8-15 & 90 & 18 & 1.5 & $0-4$ & 50 & 10 \\
\hline & $50-74$ & 27 & 9 & $6-14$ & 85 & 23 & 1 & $0-3$ & 48 & 13 \\
\hline & 75-89 & 20 & 6 & 4-10 & 70 & 14 & 0 & $0-1$ & 20 & 4 \\
\hline & $90+$ & 17 & 4 & $2-8$ & 47 & 8 & 0 & $0-1$ & 18 & 3 \\
\hline
\end{tabular}

${ }^{+} 0.001, p<0.01$, Spearman correlation for the number of issues selected; ${ }^{*} 0.001, p<0.01$, Spearman correlation for the number of specialists selected; ${ }^{++} p<0.001$, Spearman correlation for the num ber of issues selected; ** $p<0.001$, Spearman correlation for the number of specialists selected; none of the other patient characteristics were associated at $p<0.01$ with the number of issues or spe cialists selected according to the Mann-Whitney test (gender, clinical T, N, reconstruction, RT, surgery) or Kruskal-Wallis test (site, treatment); RT: radiotherapy; IQR: interquartile range; PCI: Pa tient Concerns Inventory; UW-QOL: University of Washington Quality of Life Questionnaire.

those who underwent surgery without RT selected salivation and depression (33\%), while one-quarter selected strategies to confront the disease and the treatment (24\%) and mood (29\%). The physical domain score was significantly associated with the selection of items for appetite, mouth opening, pain in head and neck, swallowing, swelling, recreation, relationships, speech/voice/being understood and fear of adverse events as well as selection of dentist, speech pathologist and oncologist/radiotherapist. The socio-emotional domain score was significantly associated with the items for appetite, chewing/eating, mouth opening, swallowing, taste, feeding tube, speech/voice/ being understood and memory as well as speech pathologist and oncologist/radiotherapist. Patients with UW-QOL composite scores of below 50 were particularly affected.

Additional concerns and specialists that were not present in the original instrument were suggested by the patients under the item "others." These items and specialists included the following: spouse/partner (twice), gastroesophageal reflux, follow-up, hair loss, choking, dementia, quality of life, transportation to hospital (displacement/cost), health insurance, dependence on others to provide support in general, diabetes, alternative treatments, burning tongue, sensation of suffocation, geriatrician, professor of physical education specialized in oncology, nose-ear-throat specialist, neurologist, acupuncturist, hematologist, vascular physician, dermatologist (four times), gastroenterologist, nephrologist, ophthalmologist and orthopedist.

\section{Discussion}

The assessment of HRQOL of patients with HNC is typically measured using specific questionnaires that cover a complex conceptual framework involving physical, psychological and social domains. ${ }^{18}$ Worldwide, the most widely used questionnaires are the EORTC QLQ-H\&N35, ${ }^{19}$ the UW-QOL ${ }^{3,15,16}$ and FACT the H\&N. ${ }^{20}$

The conception and main goals of the PCI are different from HRQOL questionnaires available in Brazil, since it enables the health team to know in real time the priorities and concerns raised by patients, helping them to target and structure consultations and promote shared decision-making and multidisciplinary care. ${ }^{10}$ Moreover, the PCI encompasses a wide range of different concerns in diverse areas of the patient's life, which may be affected by the disease and/or treatment. Given the importance of this topic as well as the increased survival of individuals with HNC, the availability of a specific and easy-to-use clinical tool in Brazilian Portuguese is necessary to allow physicians to identify the concerns that permeate the life of these patients during and after their treatment and to facilitate any referrals or clarifications they require. Especially in busy referral medical centers, this instrument could help to focus the clinical consultation on the patients needs, promote a more comprehensive multidisciplinary care, which could result in a more personalized approach.

Although the study consisted mainly of patients with tumors of the oral cavity, oropharynx and larynx with a few cases of nasopharynx, hypopharynx, nasal cavity, maxillary sinus, and other HNC sites, the patient sample was fully represented by different tumor stages, treatment modalities and time intervals from diagnosis. Several other concerns and specialists not in the original instrument emerged during this study, which should be considered in future refinements of the PCI, a factor already considered by the original author (SNR) since the initial conception of the PCI. ${ }^{10}$

Overall, patient impressions about the PCI were largely favorable, as illustrated by the following comments: "Some- 
times, the doctor is unwilling to talk about some subjects; I do not know if it is lack of time or if it is because they don't want to trouble the patient... Many doctors want to protect the patient..." "Everything I feel is written there...!" "This questionnaire was very important to me; they could create an explanatory leaflet about everything that can happen to us because of the treatment..." "From the common concerns and common cases, group meetings could be established for patients and families..." "... This questionnaire is like an anticipated dialogue with the doctor...!" "This was the first time someone listened to me and asked how I felt. I have already taken this initiative with respect to the hospital, but it is the first time someone from the hospital has taken this initiative in relation to me..." "... In several years of continuous treatment at the hospital, this is the first time I've been formally consulted on topics related to the treatment. I think that, with this, I could contribute more with my experiences to enhance the hospital services..." "People being concerned about others is very assuring."

The item selected most often by patients was fear of their cancer returning (also named fear of recurrence, FoR), followed by dry mouth, chewing/eating, and the indication for a speech therapist and dentist. Other studies that used the PCI-H\&N have also found FoR to be the most common concern that patients with HNC want to discuss in clinics, ${ }^{10,21,22}$ especially in patients aged less than 65 years, who seemed to experience more significant FoR, ${ }^{23,24}$ which is in accordance with the findings of our study. Using the PCI during clinical routine practice seems to "allow"/facilitate patients to talk about this heavy burden with the clinical team, which is usually not addressed during consultation and may cause detrimental effects on patients psychological well-being. ${ }^{25}$

For PCI validation, we considered that the most important step of cultural validation in Brazilian Portuguese was the rigorous process of translation and back-translation, as well as the cultural adaptation of some words and expressions not well-understood or misinterpreted by Brazilian patients. However, we decided to test the construct validity of the Brazilian version comparing its results with the UW-QOL scores. The results showed important associations between the Brazilian Portuguese version of PCI and the UW-QOL scores. Patients with low UW-QOL scores selected a higher number of issues for discussion in the PCI, confirming the hypothesized scenario of low QOL scores being related to the number of issues raised on PCI.

Overall, the results of our study demonstrated good user feasibility/acceptability of the PCI and significant correlations of PCI with clinical variables and the UW-QOL, which is in accordance with the expectations related to this instrument and demonstrates the usefulness of the PCI in our population.

The incorporation of the PCI-H\&N into clinical practice has the potential of offering patients the freedom to choose whether they wish to address some of their concerns at any point during treatment with members of the clinical team, supporting the adoption of appropriate strategies and referrals, which may in turn minimize the impact of the disease and its treatment in different areas of the patient's life. In its original format created in the UK, the PCI and UW-QOL were completed by patients using a touch-screen computer (TST) and the responses were instantly available to the doctor. In the present study, touch-screen technology was not available and patients received a printed version of the translated PCI. The concomitant use of a HRQOL instrument such as the UW-QOL allows patients with any disease or treatment-related dysfunction to be identified and thus promote an opportunity for the clinician to discuss aspects where patients are performing badly even though the patient might not have selected related items on the PCI for discussion. In this context, PCI can be used alone either on paper or via touch screen or combined with a HRQOL questionnaire prior to consultation.

\section{Conclusion}

To sum up, PCI is the only clinical tool of its class currently available for patients with $\mathrm{HNC}$ that is fast, easy to apply, and can be used alone or in combination with HRQOL questionnaires. The translation and adaptation of the PCI into Brazilian Portuguese can be considered successful, and the results demonstrate its applicability and sensitivity, making the Brazilian Portuguese version a valuable tool that can be used in the Brazilian population. International comparison would give valuable insight into the cross-cultural patient experience of HNC survivorship.

Further studies using the Brazilian Portuguese version of the PCI must evaluate the adherence of the clinical staff to this new tool, the optimization of communication between patients and physicians, as well as verify if the previously undiagnosed concerns of the patients were actually identified and discussed, assessing if there were any changes in the number of referrals to other members of the multidisciplinary team, and exploring the changes in patient concerns over time.

\section{ACKNOWLEDGMENTS}

Ivy Jungerman thanks the Brazilian Federal Agency for the Support and Evaluation of Graduate Education (Capes - Coordenação de Aperfeiçoamento de Pessoal de Nível Superior) for their financial support. 


\section{Conflict of Interest}

The authors declare no conflict of interest.

\section{Resumo}

Inventário de Preocupações dos Pacientes com câncer de cabeça e pescoço: adaptação cultural brasileira

Objetivo: O objetivo deste estudo foi traduzir, adaptar culturalmente e avaliar o Inventário de Preocupações dos Pacientes - Cabeça e Pescoço (IPP-CP) em uma série consecutiva de pacientes brasileiros.

Método: Este estudo incluiu pacientes adultos tratados por câncer do trato aerodigestivo superior (TADS). A tradução e a adaptação cultural do IPP-CP seguiram diretrizes internacionalmente aceitas e incluíram uma amostra piloto de pacientes que completaram a primeira versão em português do IPP-CP. O uso, a viabilidade e a aceitabilidade do IPP-CP foram testados posteriormente, em uma série consecutiva de pacientes com câncer do TADS que completaram a versão final em português do PCI e uma versão em português do questionário de qualidade de vida da Universidade de Washington (UW-QOL). As associações entre os escores físicos e socioemocionais do UW-QOL e do IPP foram analisadas.

Resultados: Vinte pacientes participaram da pesquisa piloto (processo de adaptação cultural e tradução), e 84 pacientes foram analisados no estudo de validação cultural. As questões mais selecionadas foram: medo de o câncer voltar, boca seca, mastigação/comer, fala/voz/ser compreendido, deglutição, saúde dental/dentes, ansiedade, fadiga/cansaço, paladar e medo de eventos adversos. Os três especialistas mais selecionados foram fonoaudiólogo, dentista e psicólogo. Relações estatisticamente significativas entre IPP e UW-QOL foram encontradas.

Conclusão: A tradução e a adaptação cultural do IPP para o português foram bem-sucedidas, e os resultados demonstram a viabilidade e a utilidade da ferramenta, tornando-a valiosa para uso na população brasileira com câncer de CP.

Palavras-chave: questionários, qualidade de vida, neoplasias de cabeça e pescoço, validade e reprodutibilidade, pesquisa de resultados.

\section{REFERENCES}

1. Crozier E, Sumer BD. Head and neck cancer. Med Clin North Am. 2010; 94(5):1031-46.

2. Wünsch Filho V. The epidemiology of laryngeal cancer in Brazil. São Paulo Med J. 2004; 122(5):188-94.

3. Hassan SJ, Weymuller EA Jr. Assessment of quality of life in head and neck cancer patients. Head Neck. 1993; 15(6):485-96
4. Vartanian JG, Carvalho AL, Yueh B, Priante AV, de Melo RL, Correia LM, et al. Long-term quality of life evaluation after head and neck cancer treatment in a developing country. Arch Otolaryngol Head Neck Surg. 2004; 130(10):1209-13.

5. Kazi R. Surgical voice restoration following total laryngectomy. J Cancer Res Ther. 2007; 3(4):188-89.

6. Kazi R, De Cordova J, Kanagalingam J, Venkitaraman R, Nutting CM, Clarke $\mathrm{P}$, et al. Quality of life following total laryngectomy: assessment using the UW-QOL scale. ORL J Otorhinolaryngol Relat Spec. 2007; 69(2):100-6.

7. Morton RP, Izzard ME. Quality-of-life outcomes in head and neck cancer patients. World J Surg. 2003; 27(7):884-9.

8. Murphy BA, Ridner S, Wells N, Dietrich M. Quality of life research in head and neck cancer: a review of the current state of the science. Crit Rev Oncol Hematol. 2007; 62(3):251-67.

9. Sayed SI, Elmiyeh B, Rhys-Evans P, Syrigos KN, Nutting CM, Harrington $\mathrm{KJ}$, et al. Quality of life and outcomes research in head and neck cancer: a review of the state of the discipline and likely future directions. Cancer Treat Rev. 2009; 35(5):397-402.

10. Rogers SN, El-Sheikha J, Lowe D. The development of a Patients Concerns Inventory (PCI) to help reveal patients concerns in the head and neck clinic. Oral Oncol. 2009; 45(7):555-61.

11. Patient Concerns Inventory. Available from: http://www.patient-concernsinventory.co.uk

12. Ghazali N, Kanatas A, Langley DJ, Scott B, Lowe D, Rogers SN. Treatment referral before and after the introduction of the Liverpool Patients Concerns Inventory (PCI) into routine head and neck oncology outpatient clinics. Support Care Cancer. 2011; 19(11):1879-86.

13. Guillemin F, Bombardier C, Beaton D. Cross-cultural adaptation of health-related quality of life measures: literature review and proposed guidelines. J Clin Epidemiol. 1993; 46(12):1417-32.

14. Beaton DE, Bombardier C, Guillemin F, Ferraz MB. Guidelines for the process of cross-cultural adaptation of self-report measures. Spine (Phila Pa 1976). 2000; 25(24):3186-91.

15. Rogers SN, Lowe D, Yueh B, Weymuller EA. The physical function and social-emotional function subscales of the University of Washington Quality of Life questionnaire. Arch Otolaryngol Head Neck Surg. 2010; 136(4):352-7.

16. Vartanian JG, Carvalho AL, Yueh B, Furia CL, Toyota J, McDowell JA, et al. Brazilian-Portuguese validation of the University of Washington Quality of Life Questionnaire for patients with head and neck cancer. Head Neck. 2006; 28(12):1115-21.

17. Anthoine E, Moret L, Regnault A, Sébille V, Hardouin J-B. Sample size used to validate a scale: a review of publications on newly-developed patient reported outcomes measures. Health Qual Life Outcomes. 2014; 12:176.

18. Llewellyn CD, McGurk M, Weinman J. Are psycho-social and behavioural factors related to health related-quality of life in patients with head and neck cancer? A systematic review. Oral Oncol. 2005; 41(5):440-54.

19. Bjordal K, Ahlner-Elmqvist M, Tollesson E, Jensen AB, Razavi D, Maher EJ, et al. Development of a European Organization for Research and Treatment of Cancer (EORTC) questionnaire module to be used in quality of life assessments in head and neck cancer patients. EORTC Quality of Life Study Group. Acta Oncol. 1994; 33(8):879-85.

20. List MA, D’Antonio LL, Cella DF, Siston A, Mumby P, Haraf D, et al. The performance status scale for head and neck cancer patients and the functional assessment of cancer therapy-head and neck scale. A study of utility and validity. Cancer. 1996; 77(11):2294-301.

21. Rogers SN, Scott B, Lowe D, Ozakinci G, Humphris GM. Fear of recurrence following head and neck cancer in the outpatient clinic. Eur Arch Otorhinolaryngol. 2010; 267(12):1943-9

22. Kanatas A, Ghazali N, Lowe D, Udberg M, Heseltine J, O’Mahony E, et al. Issues patients would like to discuss at their review consultation: variation by early and late stage oral, oropharyngeal and laryngeal subsites. Eur Arch Otorhinolaryngol. 2013; 270(3):1067-74.

23. Llewellyn CD, Weinman J, McGurk M, Humphris G. Can we predict which head and neck cancer survivors develop fears of recurrence? J Psychosom Res. 2008; 65(6):525-32.

24. Humphris GM, Rogers SN, McNally D, Lee-Jones C, Brown, JS, Vaughan ED. Fear of recurrence and possible cases of anxiety and depression in orofacial cancer patients. Int J Oral Maxillofac Surg. 2003; 32(5):486-91.

25. Ghazali N, Cadwallader E, Lowe D, Humphris G, Ozakinci G, Rogers SN Fear of recurrence among head and neck cancer survivors: longitudinal trends. Psychooncology. 2013; 22(4):807-13. 